\title{
Research on the Protection and Development of Clothing Brand at Internet + Era
}

\author{
Wen Gan \\ Jiangxi Garment Institute, Jiangxi, Nanchang, China, 330201
}

Keywords: Internet +, Network, Clothing Brand, Protection, Development

\begin{abstract}
With the popularity of mobile phones and the Internet, the network has become an integral part of people's lives. As the traditional livelihood of the industry, the apparel industry to fully use the network platform to promote, publicity, rally, marketing functions, and constantly establish, protect and enhance the brand influence and visibility, enhance the quality of Chinese clothing brand. This article mainly discusses the existing problems in the protection and development of Chinese clothing brand and puts forward some countermeasures and countermeasures for reference.
\end{abstract}

\section{Introduction}

The popularity of the network has changed Chinese consumption patterns, people are increasingly accustomed to the completion of transactions through the network, Alibaba, Jingdong Mall, Suning Tesco, etc. to the creation of the traditional clothing business model brought a lot of impact. Network platform update cycle is short, easy to fake, the threshold is low, how in the electronic, network platform to maintain the brand advantage has become a lot of brand clothing companies need to consider the issue.

\section{The Impact of Online Shopping on the Brand Clothing Business}

First, online shopping makes consumption more convenient. Consumers use mobile phones, computers and other tools to browse shopping information, compare the price of various clothing brands, quality and style, can save a lot of shopping time, a variety of fast logistics services greatly stimulate the desire of consumers shopping. Second, the brand promotion way is with diversification. Sellers through the establishment of a full range of network communication platform, set the text, dialogue, search, video, pictures as a whole, making clothing transactions more efficient, interesting and intuitive. Third, it is the strict maintenance of the brand. The development of the network platform has also brought a lot of brand fraud phenomenon. Shopping evaluation is open so that consumers in the purchase of clothing more concerned about the previous consumer evaluation of clothing. All clothing enterprises must be on the clothing production, marketing and after-sales service and other aspects of strict control, to reduce the high imitation clothing on their own clothing brand image of the impact. Fourth, the price is transparent. Network platform for businesses to save a lot of inventory, rent and other costs, greatly improving the cost of clothing transactions, reducing the cost of clothing transactions, clothing market in the fierce competition makes the price of clothing more transparent. Fifth, choose to diversify. Network platform transactions provide consumers with more choice, but also to some small clothing brands to provide more opportunities to enter into other regions of the market.

\section{The Protection Research of Clothing Brand}

\subsection{The Status of Brand Protection}

Protect the clothing brand, that is, to protect the clothing brand contains all the intellectual property rights, such as the brand's network domain name, trade secrets, patents and trademarks. 
Want to make the brand in the fierce competition in an invincible position, want to enhance the core competitiveness of clothing brands and we must strengthen the brand protection efforts.

At present, Chinese brand protection is still some problems. First, the relevant departments for clothing crackdown, has taken a lot of measures, such as the opening of the mailbox, hotline, regular inspection, but these efforts are still inadequate and difficult to endure, some local governments to achieve local protection of the cost of business, some government officials In the ideological fake not enough attention, so clothing fake enterprises still have nothing to fear. Second, the clothing industry and there are many fake, plagiarism, but many brands of clothing enterprises are helpless. In the fierce competition, many clothing companies are reluctant to invest too much in the establishment of clothing brands, as one grasp only sales, they take "free rider" and "riches" of the psychological and even other brands for infringement and counterfeiting. Brand clothing enterprises only after being infringed to begin to realize the importance of brand protection, they know nothing about brand protection, which gives the brand protection has brought a lot of obstacles. Third, consumers do not have the right consumer awareness and consumption standards, poor brand awareness of protection. The market still exists a lot of worsening phenomenon, consumers in order to seek cheap and buy high imitation clothing products, greatly damaged the legitimate business interests.

\subsection{Protection Measures}

First, the government continues to increase publicity efforts, and for small garment enterprises to provide financial and policy support. Relevant government departments increase the inspection efforts, to timely protection of the brand and the practice of doing a good job and promotion. Enterprises should promptly prepare brand protection related promotional materials or materials to ensure that the brand protection of the relevant legal measures can be implemented in place. At present, many small and medium-sized garment enterprises funding shortage, they do not have more financial support to brand protection and the Government should try to provide them with technology development support, preferential policies, funds and so on. The relevant departments are still not based on the number of patents and brand awareness of clothing enterprises to carry out special funds to support. In order to better protect their own brand, each brand clothing enterprises to apply for their own brand of intellectual property protection.

Second, the enterprise continuously improves the brand awareness, the establishment of brand protection association, the use of the Internet platform for brand protection. Garment enterprises to set up a special brand protection department, reserves, training some high-quality personnel, improve the brand awareness of workers to strengthen the relevant legal knowledge of publicity and education. The clothing industry association shall hold regular exchange of experiences to promote the exchange of brand protection programs and measures between garment enterprises, prevent and combat infringement, and provide legal, technical, information and personnel support to the affected enterprises in time, and organize relevant personnel Infringement of the incident to deal with, coordination. In addition, the garment enterprises can also make full use of the network platform in the website registration, publicity clothing brand, so that more people understand and accept the clothing brand, improve customer loyalty, so that customers spontaneously resist high imitation products.

Third, the consumer side, to consciously resist imitation clothing, the relevant social groups should also actively join the ranks of clothing brand protection. In the face of unbridled cottage brand, counterfeit brand, consumers should dare to use the law to protect their own interests. Related social groups, such as consumer associations, they represent the interests of the vast number of consumers, must actively participate in clothing counterfeiting activities, pick up the legal weapons to actively protect the interests of consumers. 


\section{The Development Research of Clothing Brand}

\subsection{The Development Status of Local Clothing Brand}

First, China has always been a garment processing power has been used as the role of processors, leading to the lack of awareness of the clothing brand, brand awareness is weak. Second, compared with the international fashion design style, Chinese domestic fashion design style innovation is not enough, no creativity. Local brand clothing to increase the creativity of their own clothing brand cannot blindly put a variety of modern elements for random listing and piling up, but to try to make local clothing to fully demonstrate the connotation and spirit of oriental culture. Third, the local clothing brand of small, low processing costs cannot be based on long-term international market.

\subsection{Development Measures}

First, establish brand awareness and brand image. Local clothing brand should pay attention to the quality of clothing, by improving the quality of clothing to obtain consumer recognition, improve consumer confidence in the clothing establish a brand image. At the same time, in the marketing process, garment manufacturers to try to meet the reasonable demands of consumers, the establishment of customer relationship management system, as far as possible to improve consumer satisfaction and improve consumer brand loyalty.

Second, go to the international. Chinese local garment enterprises look long-term, for the brand to establish an international image, the local brand to the international. Local clothing enterprises should continue to improve their own strength, continue to learn foreign advanced management, management, design, production experience, improve the level of designers, design a high standard of clothing, the local clothing will continue to introduce the world stage.

Third, use network platform to collect and process data. Clothing enterprises can be timely through the network platform to obtain market feedback and consumer feedback. The direct purchaser of the clothing to the product feedback, indirect customer evaluation of the product, these evaluations will greatly stimulate the purchase of clothing. Garment enterprises in a timely manner to the customer's comments and suggestions to respond, take timely measures to improve customer satisfaction. Enterprises to obtain the data to do a good job analysis always concerned about the market changes in the market, the perception of customer demand for product changes in a timely manner to make predictive changes to bring surprises to customers, so that customers have a good impression on the clothing brand to establish a brand image. At the same time, enterprises should also promptly released in the official website of the latest clothing brand information and fashion information, causing customer attention, guide customers to fashion consumption, change the customer's understanding of fashion. Garment companies in the release of information at the same time not only can recover the cost of benefits, but also establish a brand image to the brand's internal factors and culture to attract the attention of customers.

Fourth, increase sales channels to promote the sustainable development of clothing brands. Clothing enterprises can buy and buy and other ways to gradually increase their sales channels, the establishment of stores, to provide customers with all aspects of service. The rapid development of e-commerce to promote the sale of clothing, local clothing enterprises through the network distribution, third-party platform, the official website to increase retail channels, expand the sales market. Through the construction of the site, garment enterprises can continue to improve the brand image, such as the creation of business alliances, search engines and advertising. On the website, the enterprise to provide consumers with the most innovative, comprehensive and true clothing information, to provide consumers with a convenient, safe, satisfied, high-quality shopping environment, shopping process and logistics services, while consumers brand culture The In addition to brand sites, garment enterprises can also effectively use a variety of media platforms, such as QQ, We-Chat, micro-blogging, etc., give full play to these media platform interactive, , To carry out a variety of business activities, continue to shape and enhance the brand image, enhance consumer awareness, improve brand influence, increase consumer loyalty to the brand, and constantly open up the sales market. Compared with the store, the shop has a greater development 
and sales space, it has no space constraints, but also to provide consumers with more choices, the opening of the shop can also to a certain extent, enhance the influence of clothing brands And visibility. Some of the emerging clothing brand in the absence of the case of the store can quickly build brand awareness. For example, the "crack silk" clothing brand, which is based on the network, set up flagship store on the site to "new students, exotic, wandering, mysterious" for the brand concept, the designer of the traditional national dress to improve the design of some modern Style of national costumes, giving a free feeling, in the 10 years of operation, the brand flagship store members have more than 150,000, in the Internet + era, the company successfully used the Internet to develop their own clothing Brand.

Fifth, carry out online shopping custom services. Clothing enterprises can use the network platform anytime, anywhere on the network to publish their own brand of goods, advertising, etc., you can also use the logistics courier, mobile phones and other technical support to carry out customized services for consumers to provide personalized service. Internet customers are highly educated and have a high payment and purchasing power of the crowd, which also determines the shop sales of clothing to be more personalized. Clothing enterprises can provide customers with "online custom, offline service" sales model, the use of network platform to provide customers with large-scale bulk custom processing services. For example, the clothing brand LAND'END, which provides consumers with goods through the network channel, set up multiple groups of shopping guide services, through chat, the 3D model of the consumer scan, combined with virtual fitting technology, to provide consumers with a variety of personality Custom selection, for them to pick out the most fit, most satisfied with the clothing. This online shopping customization service for the brand to save the "customer costs", greatly improving the consumer satisfaction, making the clothing brand can survive for a long time.

Sixth, playing brand war instead of price war. Chinese local clothing brand "exception", the brand design object for the low-key, elegant success of women, under the premise of low-key to show personal style, this unique design style attracts many fans concerned. The brand designers often participate in a variety of international fashion design exhibitions and performances, many invited and award-winning in the subtle influence of the brand clothing to enhance the heritage and value. The brand also created a "useless" brand that does not sell only exhibits, increasing brand value. With the Prada, Chanel, many local brand clothing designers are beginning to pay attention to the limited sales methods, they continue to increase the importance of the quality of clothing to reduce the number of physical stores, while enhancing the store brand image, open the official website online shopping channels, but also to limit the number of purchases, to avoid the brand clothing imitation and flooding. Many clothing enterprises in order to improve customer loyalty and satisfaction, but also to maintain the old customers, and gradually began to reduce the "price war", the physical store and the official website of the same price, not promotional discount. A brand wants to develop success, it must be unique, have their own brand culture, and adhere to their own brand concept, the continuous development of innovation, will survive

Seventh, scientific and technological innovation. Clothing enterprises should pay attention to scientific and technological innovation, through the application of some high-tech to the production of clothing, so that clothing more scientific, humane, improve the value of clothing and brand image. Such as sports shoes air cushion, anti-drilling cashmere lining function, anti-static jacket and so on. Adidas and Nike and other well-known brands with their own excellent R \& D team has become the international super brand.

Eighth, differentiated sales. In order to meet the multi-level consumer demand, clothing enterprises should be further fine division of the service market, and constantly looking for new business opportunities and markets. In the general economic conditions, people only pay attention to social, work and other occasions, dress up, after the economic conditions, consumers gradually began to pay attention to outdoor sportswear, home service and other clothing, the current clothing market in this part of the clothing brand Strength and quantity is still not enough 


\section{Conclusion}

The network has speeded up the upgrading of the clothing brand speed. Internet + era, the clothing brand to be successful and continued, not only to rely on brand quality, but also rely on brand culture, brand creation and successor to always adhere to their own brand culture, and constantly create value. At present, Chinese clothing brand network sales capacity still needs to be further strengthened, the network to the clothing brand protection and development has brought opportunities and challenges, clothing enterprises to adapt to the trend of network development, technology, brand culture and network integration, Local clothing brand development and growth.

\section{Acknowledgements}

Fund Project: This article is the Jiangxi province university humanities and social science project "Jiangxi local clothing brand protection and development research at Internet + "era" research project (issue number: JC1521)

\section{References}

[1] Liu Jing. Chinese clothing brand internationalization strategy research [D]. Baoding: Hebei University, 2008.

[2] Ren Qiang. Chinese clothing brand development problems and countermeasures analysis [J]. Enterprise Technology Development, 2010 (17)

[3] Liu Ying. Analysis of clothing brand business strategy [J]. Journal of Jilin Province Economic Management Cadre College, 2010 (2) 